Acta Poetica $36 \cdot 2$

julio-diciembre

$2015(45-59)$

\title{
Don Quijote y Sancho Panza: duelo hiperbólico
}

\author{
María Stoopen
}

Mientras don Quijote queda en Sierra Morena haciendo penitencia de amor por Dulcinea, Sancho Panza se encamina al Toboso a entregar a la amada una carta del caballero (Quijote I, 25). El escudero conoce ya la verdadera identidad de la señora que inspira los actos de su amo, "la moza labradora" Aldonza Lorenzo. El hecho de que Sancho no llegue al Toboso, y en consecuencia no vea nunca a la doncella ni le entregue ninguna carta, suscita en la descripción posterior que hace a su amo una serie de invenciones degradantes sobre la identidad de la joven construidas por el labrador a partir del imaginario rural. Se establece así un duelo hiperbólico de doble signo en donde don Quijote se ve forzado a adaptar las imágenes con que Sancho describe a Aldonza-Dulcinea, que no corresponden al ideal amoroso con que concibe a su amada (Quijote I, 30-31). Haré aquí un análisis de los recursos persuasivos que cada protagonista utiliza y del choque semántico que se establece a partir de los códigos de referencia de uno y otro. Asimismo, consideraré las consecuencias de estos episodios en la relación entre amo y escudero y la degradación creciente que sufre la imagen de la amada del caballero, gracias al poder discursivo de Sancho Panza.

PALABRAS ClAVE: Dulcinea/Aldonza, doble identidad, códigos opuestos, recursos persuasivos, duelo hiperbólico.

While Don Quixote in Sierra Morena is doing love penance for Dulcinea, Sancho Panza is routed to Toboso to give the beloved a letter by the knight (Quijote I, 25). The squire knows already the true identity of the woman who inspires his master's acts, "la moza labradora" Aldonza Lorenzo. The fact that Sancho did never get to Toboso, and therefore never sees the maid nor delivers any letter, issues in the subsequent description for his master of a series of degrading inventions about the identity of the young woman built by the farmer's rural imagery. This sets up a double-edged hyperbolic duel. Don Quixote is forced 
to match the images with which Sancho describes Aldonza-Dulcinea, that do not correspond to the ideal love with which he thinks of his beloved (Quijote I, 30-31). Herein I will make an analysis of the persuasive resources each protagonist uses and of the semantic shock established out of the reference codes. Also, I will consider the impact of these events on the relationship between master and squire and the increasing degradation of the knight's beloved image, all that due to Sancho Panza's discursive power.

KEYWORDS: Dulcinea/Aldonza, double identity, opposite codes, persuasive resources, hyperbolic duel.

Fecha de recepción: 7 de agosto de 2014

Fecha de aceptación: 12 de febrero de 2015 
Acta Poetica $36 \cdot 2$ julio-diciembre

$2015(45-59)$

\author{
María StOOPEN \\ Universidad Nacional Autónoma de México \\ Facultad de Filosofia y Letras \\ mstoopeng@gmail.com
}

\title{
Don Quijote y Sancho Panza: duelo hiperbólico
}

Es durante la estancia de don Quijote y Sancho Panza en Sierra Morena cuando Dulcinea-Aldonza empieza a cobrar protagonismo, si bien un protagonismo de segundo grado, ya que la amada no es más que una construcción imaginaria y — cabe destacar- hiperbólica del caballero de la Mancha, puesto que la moza del Toboso queda totalmente ajena al papel que el enamorado, por necesidades librescas, le hará desempeñar. ${ }^{1}$ Además de las frecuentes y exaltadas invocaciones a la dama elegida como protectora y destinataria de sus lances caballerescos, y de la desmedida solicitud del caballero a unos mercaderes toledanos para que confesaran "que no hay en el mundo todo doncella más hermosa que la Emperatriz de la Mancha, la sin par Dulcinea del Toboso" (I, 4), don Quijote ahora se dispone a hacer penitencia y convertirse en loco enamorado a causa de "una luenga ausencia y unos imaginados celos [...] de aquella ingrata y bella, término y fin de toda humana hermosura" (I, 25). ${ }^{2}$ Buscará, entonces, tener mayor presencia ante ella y darle a conocer sus amores al resolver escribirle una carta que Sancho llevará al Toboso. Esta decisión hará posible la materialización de la amada por lo

${ }^{1}$ En "Los íconos subvertidos en el Quijote" me ocupo de la naturaleza sui géneris de Dulcinea (31-62).

2 Para los antecedentes literarios de la penitencia, véase Allen 2004: 67-68. 
menos ante los ojos del escudero, creencia con que se queda el enamorado penitente en Sierra Morena en tanto el mensajero tomará camino para cumplir el encargo de su amo.

Por otro lado, la revelación que momentos antes don Quijote había hecho a Sancho sobre la verdadera identidad de su señora - hija de Lorenzo Corchuelo y Aldonza Nogales- descubre las entretelas de la realidad y deja en poder de Sancho no sólo la imagen sino el destino de Dulcinea, ocasión que el escudero aprovecha para concebirla en términos de su propio estrato social y construir un malicioso retrato caricaturesco, fabricación denigrante - tan imaginaria e hiperbólica como la del caballero - ${ }^{3}$ que rebaja tanto a la "princesa de quien vuestra merced estaba enamorado" $(I, 25)$ como a la propia "moza labradora de muy buen parecer" (I, 1) — escueta descripción de Aldonza Lorenzo hecha por el narrador en el primer capítulo y único referente confiable en términos realistas para el lector-. De este modo, a partir de la información que el Caballero de la Triste Figura dio a su escudero en Sierra Morena, los personajes tendrán perspectivas diametralmente opuestas con respecto a la doncella, de acuerdo con la visión del mundo de cada quien; uno mantendrá una tendencia idealizadora, y el otro degradante. ${ }^{4}$ Así, el retrato de la moza del Toboso que Sancho traza provoca las primeras diferencias entre los andantes manchegos con respecto a la señora de don Quijote, quien en uso de su autoridad hace una reprensión al escudero:

${ }^{3}$ Sancho confesará más adelante no haberla visto nunca:

“-[...] En lo de la hermosura no me entremeto, que en verdad, si va a decirla, que entrambas [Dulcinea y la princesa Micomicona] me parecen bien, puesto que yo nunca he visto a la señora Dulcinea.

—CÓmo que no la has visto, traidor blasfemo? — dijo don Quijote-. Pues ¿no acabas de traerme ahora un recado de su parte?

-Digo que no la he visto tan despacio - dijo Sancho-, que pueda haber notado particularmente su hermosura y sus buenas partes punto por punto; pero así a bulto me parece bien" (I, 30).

Por su parte, el narrador informa que "Sancho [...] ya estaba cansado de mentir tanto y temía no le cogiese su amo a palabras; porque, puesto que él sabía que Dulcinea era una labradora del Toboso, no la había visto en toda su vida" (I, 31).

4 En "Dulcinea entre el simulacro y el espectro" me ocupo de las construcciones imaginarias que los personajes, principalmente los protagonistas, hacen de la amada de don Quijote (139-151). 
-Ya te tengo dicho antes de agora muchas veces, Sancho [...], que eres muy grande hablador y que, aunque de ingenio boto, muchas veces despuntas de agudo; mas para que veas cuán necio eres tú y cuán discreto soy yo, quiero que me oyas un breve cuento (I, 25).

Con el equívoco cuentecillo don Quijote cree conseguir la defensa de su perspectiva y, al hacer patente la naturaleza poética e imaginaria de la dama, ${ }^{5}$ acepta su origen llano y admite que la transformación no es más que resultado de su propia voluntad amorosa: “- [...] Así que, Sancho, por lo que yo quiero a Dulcinea del Toboso, tanto vale como la más alta princesa de la tierra. Sí, que no todos los poetas que alaban damas debajo de un nombre que ellos a su albedrío les ponen, es verdad que las tienen" (I, 25).

En Sierra Morena, pues, don Quijote ha puesto en manos de Sancho las armas con que el escudero podrá manipular a su conveniencia la identidad de la amada del caballero. Sin embargo, en esta ocasión, a pesar de la caricatura que Sancho hace de Aldonza Lorenzo, las discordancias no pasan a mayores y no se entabla gran discusión entre ellos sobre la contradictoria condición de la moza.

Capítulos adelante (I, 31), será en torno al tema fundamental del mensaje de amor escrito y enviado por el caballero enamorado y la descripción que Sancho podrá hacer de la amada tras haberla visto que el escudero elaborará una serie de mentiras no sólo sobre la imagen de Aldonza, que él inventa en consonancia con el que había construido en Sierra Morena antes de su partida, sino con respecto a la entrega de la hermosa carta de amor que el caballero penitente escribió a Dulcinea y que encabeza de la siguiente manera: "Soberana y alta señora" (I, 25), epítetos que Sancho degrada en su intento de reconstruir de memoria la misiva, según lo solicitarán el cura y el barbero cuando lo encuentran en el camino: "Alta y sobajada señora" (I, 26), y que repetirá luego ante el caballero enamorado: “- - [...] y si algo se me acuerda, es aquello del sobajada, digo, del soberana señora [...]” (I, 30).

${ }^{5}$ En "Trazos escénicos en dos episodios del Quijote. Las poéticas de la imitación y el desnudamiento" analizo la revelación que el caballero hace sobre la identidad de su dama (125-137). 
Como es sabido, Sancho Panza nunca llega al Toboso con su embajada, pues luego de toparse con los amigos de don Quijote, quienes van en su búsqueda para reducirlo de nuevo a la domesticidad, vuelve con ellos a Sierra Morena a persuadir al penitente de abandonar su empresa. Así, queda trunca la posibilidad de que Dulcinea-Aldonza pudiera cobrar forma ante la mirada del escudero. Terminado el retiro del caballero enamorado y ya ocurrida la farsa de la princesa Micomicona, don Quijote por fin encuentra la oportunidad de hablar a solas con Sancho y preguntarle sobre el resultado de su encargo. El amo, ignorante de la verdad, solicita la descripción hasta del más mínimo gesto de la amada cuando recibió la carta del enamorado, misiva que de todos modos nunca habría llegado a sus manos, pues el propio caballero se quedó con el librillo en donde la había escrito, propiedad de Cardenio.

Durante el informe sobre la supuesta entrevista que rinde a su amo, Sancho se comportará como un narrador ventajoso e infidente ${ }^{6}$ ante un escucha no enterado de la verdad y ávido por obtener una descripción de su señora, apegada a la fabricación sublime que se ha hecho de ella. La primera falsedad del labrador, adobada con su gracia e ingenio, fue que había dictado de memoria el mensaje de amor a un sacristán. A partir de este momento se produce un duelo hiperbólico de construcciones imaginarias que oscilan entre el ideal y la caricatura, entre la dama Dulcinea y la Aldonza labradora degradada. El episodio se monta con desventaja para el enamorado, pues todos los demás - ahora los que importan son el narrador, el propio Sancho y el lector- están al tanto de que el escudero nunca llegó al Toboso. A ello hay que agregar la necesidad del caballero andante de mantenerse fiel a los códigos adoptados, ya que "el caballero sin amores era árbol sin hojas y sin fruto y cuerpo sin alma" (I, 1). En el intercambio entre ambos estarán en juego las ideas filosóficas y literarias a partir de las que don Quijote concibe el amor: contradichas, alimentadas y adaptadas a modo por Sancho.

${ }^{6}$ Booth (158-159) acuña el término unreliable narrator, el cual es retomado y traducido como narrador infidente por Avalle Arce (4-6). En este artículo - "Las voces del narrador"- el autor sostiene que en el Quijote se presenta por primera vez en la historia de la novelística un narrador de este tipo. Él se refiere al narrador del Quijote. Sin embargo, el concepto también es útil para calificar el comportamiento narrativo de Sancho. 
Así, a la suposición de don Quijote de que su dama, cual ninfa garcilasiana, ${ }^{7}$ estaba "ensartando perlas o bordando alguna empresa con oro de canutillo para este su cautivo caballero", ${ }^{8}$ Sancho responde que la encontró "ahechando dos hanegas de trigo en un corral de su casa" (I, 31). Tales visiones encontradas obligan a don Quijote a hacer una serie de ajustes hiperbólicos para rescatar la imagen disminuida de Dulcinea-Aldonza que mana del imaginario rural de Sancho, contemplaciones que resultan extremadamente graves para el caballero, pues ahora surgen del fingido encuentro de su escudero con la doncella - puras invenciones llenas de socarronería, hechos nunca presenciados por él, formulados a partir de la desnuda identidad de Dulcinea-Aldonza-. Puesto a decir mentiras, el escudero no elegirá hacer el retrato de una princesa, como espera don Quijote, sino el de una labradora en plena faena, en un espacio amueblado con objetos del mundo rural. Resulta así un juego de estira y afloja entre ambas perspectivas, competición en la que el escudero ejercerá el poder sobre su amo con base en el falso privilegio de haber visto a Dulcinea, principal hecho que le importará probar. Las perlas que imagina don Quijote se vuelven granos de trigo en el relato de Sancho, aunque para aquél el toque de las manos amadas los han de reconvertir en perlas. Y si aceptado queda por el amante que sea trigo, ha ser "candeal o trechel", que Sancho cambia por rubión, aunque - nuevo intento por parte del enamorado - el pan salido de las manos de la dama no podrá ser más que candeal. A fin de cuentas, por muchos esfuerzos que haga don Quijote para elevar la descripción de la doncella, acabará obligado a aceptar parte de la cruda realidad que le pone enfrente el taimado Sancho y a prescindir de la estampa de la dama bordando perlas y oro de canutillo: “-Y bien — prosiguió don Quijote-, he aquí que acabó de limpiar su trigo y de enviallo al molino. ¿Qué hizo cuando leyó la carta?” (I, 31).

Por otro lado, hay que advertir también que los vocablos perla, trigo candeal o trechel, harina y, finalmente, manos — de "aquella reina de la hermosura"- forman una cadena de símiles: perlas y granos de trigo

${ }^{7}$ En la Égloga tercera, por ejemplo.

${ }^{8}$ Dado que aquí trabajo principalmente el capítulo 31 de la Primera parte, en adelante no volveré a hacer referencia a él en las citas correspondientes a ese capítulo. Sí aclararé los casos cuando las citas provengan de otros capítulos. 
son semejantes en tamaño y forma; los demás sustantivos, explícitos o implícitos, están relacionados por el color blanco, símbolo de nobleza y calidad, que el caballero necesita rescatar como dotes de su dama a pesar de los datos proporcionados por Sancho; en tanto que rubión es el trigo "más productivo, pero produce harina de peor calidad" (Cervantes 2004: I, 31, n. 4), y en una de sus acepciones significa mancha (DRAE, s.v.) por lo que el labrador-escudero está poniendo en entredicho también la belleza de Aldonza-Dulcinea en relación con los cánones poéticos y retóricos del retrato femenino ideal, vigentes a partir del siglo XII y según los cuales don Quijote construye la imagen de su amada. ${ }^{9}$ Recordemos que el narrador sólo se compromete describiéndola como una "moza labradora de muy buen parecer" (I, 1). En el duelo, Sancho se empeña en atarla a su condición de labradora y don Quijote hiperboliza su "buen parecer".

La entrega de la carta, así como el interés que el caballero enamorado supone que su dama mostró por tener noticias de él suscitan nuevos equívocos. El desdén por la misiva, según la versión de Sancho, es tomado por su amo como discreción de la doncella, y la descripción que el mensajero supuestamente hizo a Aldonza-Dulcinea de la penitencia que su enamorado hacía por ella dista de representarlo dignamente, ya que oscila entre la del penitente, el loco y el salvaje. Don Quijote, sin embargo, anota un punto a su favor al ejercer su autoridad y reprender a Sancho por haber dicho que en la industria de la penitencia maldecía su fortuna, y aprovecha la oportunidad para elevar de nuevo la imagen de su dama: “- En decir que maldecía mi fortuna dijiste mal [...], porque antes la bendigo y bendeciré todos los días de mi vida, por haberme hecho digno de merecer amar tan alta señora como Dulcinea del Toboso" $(\mathrm{I}, 31){ }^{10}$

9 "La dama de cabellos rubios, piel fina y talle esbelto es la mujer idealizada que, al menos como imagen, a partir del siglo XII, se va a contraponer a la que es 'larva del demonio' o 'puerta del infierno', ingrata descripción que nos ofrecen de lo femenino los Padres de la Iglesia. Esta nueva imagen femenina, debida en buena medida a la literatura cortés, convierte a la mujer en el centro del desarrollo poético" (González: 139).

10 "La mujer se concibe como un ser superior a quien el enamorado sirve para ser correspondido. Es la domna o senhor en función de quien giran el pensamiento y las hazañas del caballero" (Walde: 73). 
El calificativo de "alta señora" que el caballero da a su amada crea un giro anfibológico entre amo y escudero, puesto que Sancho le da un sentido literal y lo entiende como altura física ("- -Tan alta es [...] que a buena fe que me lleva a mí más de un coto", I, 31), atributo que el caballero reconvierte en "grandeza". El "olor sabeo" y la "fragancia aromática" que don Quijote supone que Sancho percibió al acercarse a la joven son transformados por el escudero en "un olorcillo algo hombruno". El precario triunfo que obtiene don Quijote en su respuesta al labrador-escudero al adjudicarle a él ese aroma, que Sancho acepta como posible, acaba siendo una nueva derrota para el amo no sólo debido a la semejanza entre el olor del escudero y el de "su merced de la señora Dulcinea", sino porque el labrador-escudero amplía la similitud al decir que "no hay que maravillarse, que un diablo parece a otro", argumento que atenta contra la jerarquía que ocupa la amada en el concepto medieval y neoplatónico del amor, puesto que ella representa el punto más alto en la escala humana, y la contemplación de su belleza mueve al sentimiento amoroso. ${ }^{11} \mathrm{El}$ caballero desoye comparación tan extrema y prefiere volver al asunto más aceptable de las faenas de la moza con el trigo así como al de la carta, que en el cuento de Sancho había quedado abandonada sobre un costal. Así, la condición de labradora de Dulcinea-Aldonza es ya un hecho ineludible para don Quijote; la verosimilitud alcanzada por Sancho en su relato se la ha impuesto. Además, de la misma manera en que el aspecto físico de Aldonza-Dulcinea resulta devaluado por el labrador - manchada, excesivamente alta, maloliente; en consecuencia, vulgar y hombruna-, el nivel espiritual que debería ocupar, dadas sus dotes, es rebajado por Sancho cuando utiliza la homología del diablo, en la cual él mismo queda implicado. De este modo, la descripción y los símiles usados por el escudero no son más que una parodia degradada de los mencionados cánones poéticos. En el fondo, Sancho está diciendo a don Quijote que Aldonza Lorenzo es una labradora igual que él.

11 "Sobre la belleza de la mujer, la ideología medieval, coincidente con el sistema de creencias religiosas, acepta la concepción que ve en 'la belleza de la mujer un espejo directo e inmediato, aunque imperfecto y perecedero, de la infinita e inmutable belleza de Dios' (Pernoud, La mujer en el tiempo de las catedrales, 113)" (González: 151). 
El asunto de la carta de amores está construido a partir de algunos equívocos. Uno es que Aldonza-Dulcinea no sabe leer, dato que los dos conocen - recordemos que el mismo don Quijote en Sierra Morena le había confiado a su escudero que Dulcinea no sabe escribir ni leer (I, 25) - . Sancho aprovecha esta verdad para informar que la amada destruyó la carta ya que "no quería dar a leer a nadie, porque no se supiesen en el lugar sus secretos" (I, 31), hecho aceptable para don Quijote, ya que esa discreción es inherente a la práctica del amor cortés. Otro es que, habiéndose quedado el original en el librillo de Cardenio, en posesión del caballero, Sancho hará de nueva cuenta una reconstrucción paródica en estilo burlesco, que tergiversa los fines para los cuales fue escrita; de este modo, la carta de que hablan los andantes manchegos es la reconstrucción de memoria que Sancho supuestamente hizo para que la trasladara un sacristán. Nosotros, lectores, suponemos cómo habría sido esa carta, pues conocemos el encabezado que el labriego le dio: "Alta y sobajada señora".

A continuación, la narración indirecta en voz de Sancho, que presume reconstruir las palabras de Dulcinea, está formulada a partir de argumentos que buscan cumplir varios propósitos: mostrar la confianza que el mensaje del emisario despertó en la moza; dar gusto a don Quijote al transmitirle el interés que ella mostró por el amor del caballero; atribuir a la dama el deseo de verlo, con el fin de hacer efectivo el intento del cura y el barbero de hacerlo salir de Sierra Morena, y confirmar a su amo que alguno de los enemigos vencidos había cumplido la orden de ir a presentarse a su señora. En su argumentación Sancho se aprovecha del propio material que le han dado las experiencias vividas junto con don Quijote y la escucha de los códigos caballerescos y del amor cortés que responden a los intereses fundamentales del caballero, saberes que son adaptados y fraseados por el escudero con vocablos y conceptos rústicos, atravesados por un tono jocoso:

- Y, finalmente, me dijo que dijese a vuestra merced que le besaba las manos, y que allí quedaba con más deseo de verle que de escribirle, y que, así, le suplicaba y mandaba que, vista la presente, saliese de aquellos matorrales y se dejase de hacer disparates y se pusiese luego luego en camino del Toboso, si otra cosa de más importancia no le sucediese, 
porque tenía gran deseo de ver a vuestra merced. Rióse mucho cuando le dije como se llamaba vuestra merced el Caballero de la Triste Figura. Preguntéle si había ido allá el vizcaíno de marras; díjome que sí y que era un hombre muy de bien. También le pregunté por los galeotes, mas díjome que no había visto hasta entonces alguno (I, 31).

No obstante, don Quijote se muestra complacido por las noticias e, igual que en la ocasión anterior, hace caso omiso de la mofa que Sancho atribuye a Dulcinea a causa del nombre caballeresco recién impuesto por el propio escudero. En relación con el nuevo interés del amante sobre qué joya le había dado la amada para agradecer las nuevas que le llevó el mensajero, según costumbre cortesana, el escudero, sabedor de que no podrá presentar ninguna prueba material de su entrevista con Dulcinea, elige productos consumibles, acordes además con el mundo labriego en el que ha situado a la doncella, y explica que ahora se acostumbra dar pan y queso, para más señas, ovejuno. El Caballero de la Triste Figura acepta el hecho pero acude a una justificación: su amada no tendría a la mano ninguna joya y, del mismo modo que con el ofrecimiento de la ínsula Barataria, hace la promesa a Sancho de que cuando la visite remediará la falta. Pero en esta ocasión el escudero, por obvias razones, no puede confiar en dicho compromiso.

Don Quijote, hasta el momento satisfecho con las explicaciones de Sancho, encamina ahora su averiguación hacia un tema que requiere explicación y conduce la conversación a sus propios terrenos imaginarios: la rapidez con que su mensajero recorrió la distancia de Sierra Morena al Toboso, trayecto que llevaría mucho más tiempo de los tres días que ocupó. Y él mismo provee los argumentos para resolver el enigma: el responsable de que así ocurriera debe de haber sido el sabio nigromante que lo protege como a todo caballero andante y le permite realizar grandes proezas, en este caso en la persona de su escudero, montado en Rocinante, para favorecer con diligencia el cumplimiento de la valiosa encomienda. Así, el cuento inventado por Sancho ha pasado ya todas las pruebas a su favor, incluida la mágica, que evidentemente él acepta puesto que conoce el recurso al que suele acudir su amo y porque le facilita la solución, que él formula en términos populares: "—Así sería - dijo Sancho - , porque a buena fe que andaba Rocinante como si 
fuera asno de gitano con azogue en los oídos" (I, 31), explicación que contamina a don Quijote, quien no sólo la acepta sino que hiperboliza haciendo participar en el prodigio a "una legión de demonios".

Zanjados los asuntos de la visita a Dulcinea y la entrega de la carta, el de la Triste Figura enfrenta ahora un dilema: obedecer el mandato de su señora de que vaya a verla - nueva prueba de que ha confiado irrestrictamente en la palabra de Sancho, a pesar de las discrepancias entre su ideal y la relación que el escudero le ha brindado - o cumplir el ofrecimiento caballeresco hecho a la princesa Micomicona de defenderla del gigante que amenaza su reino, historia inventada por el cura y en la que Dorotea colabora ingeniosamente haciéndose pasar por doncella menesterosa. Aquí se entabla otra discusión en que cada uno arguye en favor de sus intereses. El caballero comunica a Sancho que está dispuesto a socorrer primero a la princesa y, degollado el gigante, dar "la vuelta a ver a la luz que mis sentidos alumbra", quien por sus hazañas alcanzará mayor gloria y fama. La decisión del amo se revierte contra el escudero, pues pone en peligro sus intereses. Por un lado, ha sido él quien con sus exageraciones y con la intención de cumplir la solicitud de maese Pero y maese Nicolás de sacar a don Quijote de su penitencia en Sierra Morena ha inventado que la amada quiere ver a su caballero, y está en riesgo de quedar atrapado en su propia mentira; por otro, sabiendo quién es Dulcinea, tampoco puede esperar obtener ninguna ventaja de sus amores con don Quijote. A la vez, advierte el conflicto de que el caballero no se case con la princesa Micomicona, puesto que a Sancho se le iría de las manos la oportunidad inmediata de que su señor se convierta en emperador

[...] o por lo menos monarca [...] y que en siéndolo le había de casar a él, porque ya sería viudo, que no podía ser menos, y le había de dar por mujer a una doncella de la emperatriz, heredera de un rico y grande estado de tierra firme, sin ínsulos ni ínsulas, que ya no las quería (I, 26),

según reconstruye el narrador en estilo libre indirecto para que se enteren el cura y el barbero del relato de una fantasía caballeresca que había compartido el escudero con su amo capítulos atrás (I, 21) ${ }^{12}$ y que San-

12 En "Don Quijote propone, ¿el cura dispone? Del relato imaginario a la farsa" analizo las relaciones y consecuencias del relato imaginario de don Quijote y la farsa 
cho ve más viable que la posibilidad de ser gobernador de una ínsula, ofrecimiento con que el hidalgo de la Mancha lo había comprometido en las andanzas caballerescas (I, 7).

A partir de este momento, la discusión ya no se nutre de las mentiras inventadas por Sancho sino que pasa al terreno de la alucinación, de la que participan amo y escudero, pues el deseo los ha llevado a construir y alimentar su propio imaginario y a ser víctimas crédulas de la farsa trazada por el cura y escenificada por los personajes de Sierra Morena (I, 29 y 30). Así, en su alegato para inclinar a su favor la decisión de don Quijote, Sancho exagera de nueva cuenta las ventajas del matrimonio con la princesa amenazada por el gigante y pone frente a su amo el inmenso reino que recibirá como dote. La respuesta del caballero allana el camino. Ahora es él quien, por su autoridad, está en poder de decidir. Se mantiene fiel a su decisión original y al amor que profesa a su dama, y a la vez no defrauda a su escudero. Así, aun sin casarse con la princesa, "al vencer al gigante me han de dar una parte del reino, para que la pueda dar a quien yo quisiere; y en dándomela, ¿a quién quieres tú que la dé sino a ti?" (I, 31). Esta vez Sancho queda atrapado y solicita que escoja la parte de su reino "hacia la marina, porque, si no me contentare la vivienda, pueda embarcar mis negros vasallos y hacer dellos lo que ya he dicho" (I, 31).

E1 acuerdo entre ambos no se hace esperar: don Quijote cumplirá con su compromiso caballeresco de matar al gigante enemigo de Micomicona; conseguirá en recompensa una parte del reino, que le cederá a Sancho, y podrá acudir al llamado de su dama. Sin embargo, surge un nuevo amago por parte del escudero que desestabiliza el arreglo hasta aquí alcanzado. A la solicitud de discreción hecha por el amo de no decir nada a nadie sobre lo que allí concertaron, "pues Dulcinea es tan recatada, que no quiere que se sepan sus pensamientos, no será bien que yo ni otro por mí los descubra" (I, 31), presunta medida de la moza comunicada por el mensajero y que el caballero está dispuesto a cumplir, Sancho reacciona con una pregunta pertinente: “¿cómo se pueden encubrir los pensamientos de entrambos?”, ¿cómo, cuando los enemigos

que monta el cura para sacar al caballero de Sierra Morena y devolverlo a su aldea (169-175). 
vencidos por don Quijote van a presentarse ante su señora, tema tratado por él en su fingido coloquio con la moza y corroborado por la supuesta visita del "vizcaíno de marras"? Don Quijote, airado, tacha de necio y de simple a su escudero y recurre al argumento de que las damas pueden tener muchos caballeros que las sirvan, pero pisa terrenos peligrosos al definir ese servicio:

-Porque has de saber que en este nuestro estilo de caballería es gran honra tener una dama muchos caballeros andantes que la sirvan, sin que se estiendan más sus pensamientos que a servilla por solo ser ella quien es, sin esperar otro premio de sus muchos y buenos deseos sino que ella se contente de acetarlos por sus caballeros (I, 31).

Sancho restituye a lo divino ese tipo de amor, de manera tan atinada que don Quijote no puede menos que reconocer: “—iVálate el diablo por villano [...], y qué de discreciones dices a las veces! No parece sino que has estudiado" (I, 31).

No obstante que el labriego reconoce que no sabe leer, triunfa en el último desafío. Aunque imaginarios los dos discursos, en su favor han obrado no sólo el pretendido privilegio del testimonio visual sino un relato coherente y, en sus términos, verosímil, además de ciertas intervenciones razonables. Por su parte, los eventuales triunfos de don Quijote han sido fruto del ejercicio tanto de su autoridad como del poder que le otorga ser miembro de la caballería andante y amo del escudero.

Para terminar sólo quiero referirme a la suerte de Dulcinea. Con respecto a ella, podemos afirmar que imagen es destino. Si aquellos mercaderes de la Mancha habían solicitado al caballero quien los intercepta que para poder cumplir su deseo "vuestra merced sea servido de mostrarnos algún retrato de esa señora, aunque sea tamaño como un grano de trigo; que por el hilo se sacará el ovillo" (I, 4), Sancho le presenta una estampa de la amada muy distante del modelo ideal, que por lo pronto no modifica el punto de vista de don Quijote, ya que él ha decidido: "píntola en mi imaginación como la deseo, así en la belleza como en la principalidad" (I, 25). Habrá que esperar a la Segunda parte (1615) para que se produzca el irremediable desaliento. 


\section{BIBLIOGRAFÍA}

Allen, John JaY. "Lecturas del Quijote. I, 24-26", en Don Quijote de la Mancha. Volumen complementario, edición del Instituto Cervantes 1605-2005 dirigida por Francisco Rico. Barcelona: Instituto Cervantes / Galaxia Gutenberg / Círculo de Lectores / Centro para la Edición de los Clásicos Españoles, 2004: 66-69.

Avalle Arce, Juan Bautista. "Las voces del narrador”, en Ínsula, 538 (1991): 4-6.

Booth, Wayne C. The Rhetoric of Fiction. Chicago: The University of Chicago Press, $2^{\text {da }}$ ed., 1983: 158-159.

Cervantes, Miguel de. El ingenioso hidalgo don Quijote de la Mancha. Versión en línea del Centro Virtual Cervantes. Disponible en $<$ http://cvc.cervantes.es/obref/quijote/edicion/parte1/parte02/cap11/default.htm $>[$ Fecha de consulta: 21 de julio de 2014].

Cervantes, Miguel de. Don Quijote de la Mancha (con un volumen complementario). Estudio preliminar de Fernando Lázaro Carreter, ed. del Instituto Cervantes 1605-2005 dirigida por Francisco Rico, Barcelona: Instituto Cervantes / Galaxia Gutenberg / Círculo de Lectores / Centro para la Edición de los Clásicos Españoles, 2004.

Diccionario de la lengua española. Real Academia Española. Versión en línea disponible en $<$ http://www.rae.es/diccionario-de-la-lengua-espanola $>$ [Fecha de consulta: 21 de julio de 2014].

GonzÁlez, Aurelio. "La imagen de la dama cortés", en Voces de la Edad Media. México: Universidad Nacional Autónoma de México, 1993: 139-155.

Pernoud, Regine. La mujer en el tiempo de las catedrales. Barcelona: Juan Granica, 1982.

Stoopen, María. Cervantes transgresor. México: Universidad Nacional Autónoma de México, 2010.

StOopen, María. "Los íconos subvertidos en el Quijote", en Cervantes transgresor. México: Facultad de Filosofía y Letras, Universidad Nacional Autónoma de México, 2010.

StOoPen, María. "Don Quijote propone, ¿el cura dispone? Del relato imaginario a la farsa", en Cervantes transgresor. México: Facultad de Filosofía y Letras, Universidad Nacional Autónoma de México, 2010.

WALde Moheno, LILLIAN vON DER. "El amor", en Introducción a la cultura medieval. Aurelio González y María Teresa Miaja de la Peña (coords.). México: Universidad Nacional Autónoma de México, 2005: 67-78. 